\title{
Publisher Correction: Deciphering photocarrier dynamics for tuneable high-performance perovskite-organic semiconductor heterojunction phototransistors
}

Yen-Hung Lin (1), Wentao Huang, Pichaya Pattanasattayavong (D), Jongchul Lim (1), Ruipeng Li, Nobuya Sakai, Julianna Panidi (1D, Min Ji Hong, Chun Ma, Nini Wei, Nimer Wehbe, Zhuping Fei, Martin Heeney (D), John G. Labram (1), Thomas D. Anthopoulos (1) \& Henry J. Snaith (1)

Correction to: Nature Communications https://doi.org/10.1038/s41467-019-12481-2, published online 2 October 2019.

In the original version of this article, the unit in the right $y$-axis of Fig. $4 \mathrm{c}$ was mislabelled as $10^{12}$. The unit should be $10^{17}$. This has been corrected in the PDF and HTML versions of the Article.

Published online: 08 June 2020

(c) (i) Open Access This article is licensed under a Creative Commons Attribution 4.0 International License, which permits use, sharing, adaptation, distribution and reproduction in any medium or format, as long as you give appropriate credit to the original author(s) and the source, provide a link to the Creative Commons license, and indicate if changes were made. The images or other third party material in this article are included in the article's Creative Commons license, unless indicated otherwise in a credit line to the material. If material is not included in the article's Creative Commons license and your intended use is not permitted by statutory regulation or exceeds the permitted use, you will need to obtain permission directly from the copyright holder. To view a copy of this license, visit http://creativecommons.org/licenses/by/4.0/.

(C) The Author(s) 2020 